\title{
Phát triển sản phẩm mói: rủi ro và cơ hội cho doanh nghiệp
}

\author{
Trần Minh Thành
}

Chi tiết

Chuyên mục: Kinh tế

Được viết ngày Chủ nhật, o3 Tháng 72016 09:25

Đổi mói sáng tạo là yêu cầu bức thiết để có thể tồn tại và phát triển trong mồi trường kinh doanh toàn cầu như hiện nay. Tuy nhiên, vẫn còn nhiều thách thức đang chờ đón doanh nghiệp (DN).

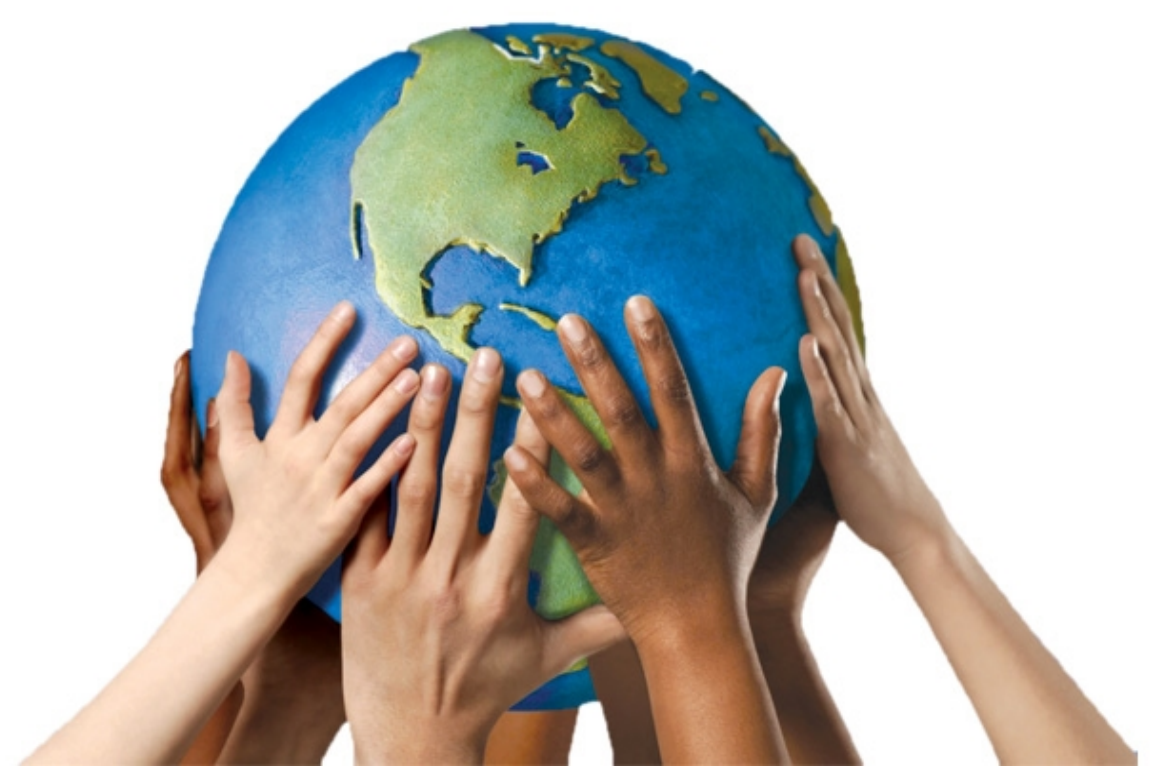

\section{Lọi thế từ sáng tạo}

Khách du lịch đến An Giang, đặc biệt là Châu Đốc, rất thích thú khi mua được những đặc sản miền Tây làm quà cho người thân. Bên cạnh các loại mắm nổi tiếng khách du lịch hay mua về làm quà, năm qua, vùng này còn có những món ăn được chế biến công nghiệp mang đặc trưng rất riêng như trà râu bắp, chả giò chay làm từ đậu nành - bắp non, bắp non tẩm bột chiên... của Công ty Antesco.

Đó là những sản phẩm mới được nhóm nghiên cứu sáng tạo Phòng R\&D Công ty Antesco dày công nghiên cứu thời gian qua. Trước đó, Công ty cũng nghiên cứu một số món rất đặc biệt như cá linh kho nước mía, đậu nành rau...

Đây là hành trình khát khao nghiên cứu cái mới, sáng tạo mà ông 
Huỳnh Quang Vinh, Phó tổng giám đốc Công ty Antesco, cùng nhóm nghiên cứu của Công ty dốc lòng để cho ra những sản phẩm mới phục vụ người tiêu dùng, giúp Công ty phát triển trong môi trường hội nhập.

Cũng như Antesco, những năm gần đây, các sản phẩm thực phẩm chế biến từ thủy sản của thương hiệu Sài Gòn Food rất được người tiêu dùng trong nước ưa chuộng. Trong lĩnh vực thực phẩm chế biến, nhờ đổi mới sáng tạo mà Sài Gòn Food dù ra đời sau nhưng đã có được chỗ đứng vững chắc trên thị trường. Năm qua, Sài Gòn Food đã được Thủ tướng Chính phủ tặng bằng khen đồi mới sáng tạo.

Bí quyết thành công của Sài Gòn Food là nhờ tận dụng công nghệ cao khi làm hàng cho các đối tác Nhật, Công ty đã nghiên cứu cho ra đời những sản phẩm đáp ứng nhu cầu ngày càng cao của người tiêu dùng. Mới đây, Sài Gòn Food trình làng cá hấp, cá trứng một nắng, trước đó là cháo dinh dưỡng và các sản phẩm thủy sản ăn liền. Mỗi năm, Công ty đưa ra thị trường không dưới 10 sản phẩm mới.

Chia sẻ về vấn đề này, bà Lê Thị Thanh Lâm, Tổng giám đốc Công ty Thương mại Sài Gòn Food, cho rằng, với ngành thực phẩm, người tiêu dùng rất thích đổi mới khẩu vị, tiếp cận những sản phẩm tiện dụng, mới lạ. Một trong những yếu tố thành công của Sài Gòn Food thời gian qua là đã đẩy mạnh công tác đổi mới sáng tạo.

Đây không chỉ là vấn đề của Sài Gòn Food mà còn là yếu tố quyết định sự thành công đối với DN Việt Nam. "Đổi mới sáng tạo là yếu tố sống còn đối với DN. Trong thời gian tới, nếu không đầu tư cho đổi mới sáng tạo thì khó có thể cạnh tranh với hàng ngoại nhập sẽ tràn lan trên thị trường", bà Thanh Lâm nói.

Cùng với Antesco, Sài Gòn Food, Công ty CP Sao Mai cũng thực hiện một quy trình đổi mới sáng tạo không ngừng nghỉ để cho ra những sản phẩm mang đặc trưng riêng: đồng phục và áo chống đạn cho cảnh sát Mỹ. Mặc dù có khách hàng lớn như thế nhưng lãnh đạo Sao Mai vẫn cho rằng phải chủ động đưa ra những sản phẩm khác biệt với thị trường mới có thể tạo được sự tăng trưởng đột phá. Sao Mai tìm đến với bộ công cụ đo năng lực đổi mới sáng tạo của DN i2Metrix do Trung tâm Kinh doanh và Hỗ trợ doanh nghiệp (BSA) và Công ty Nghiên cứu kinh tế và Tư vấn kinh doanh Dan Houtte \& Partners Ltd (DHVP) cùng phát triển.

\section{Thách thức nguồn nhân lực}

Đổi mới sáng tạo là vấn đề rất quan trọng nhưng tại sao DN Việt Nam vẫn chưa mạnh dạn đầu tư? Đó là vì đầu tư cho đổi mới sáng tạo rất tốn kém và nhiều rủi ro. Chia sẻ từ $\mathrm{DN}$ cho thấy, không phải $100 \%$ sản phẩm mới ra mắt đều thành công. Khi nghiên cứu sản phẩm mới, muốn đưa ra thị trường thì phải tốn chi phí rât lớn cho các hoạt động quảng bá để người tiêu dùng biết đến và chấp nhận sản phẩm. 
Để sản phẩm cháo dinh dưỡng Sài Gòn Food được người tiêu dùng chấp nhận như hiện nay, Công ty đã phải phát hàng trăm ngàn sản phẩm mẫu đến 500 trường mẫu giáo. Trong năm đầu tiên, doanh số của sản phẩm này chỉ bằng chi phí làm marketing.

Không có kinh phí để chạy quảng cáo trên báo chí, truyền hình như các $\mathrm{DN}$ nước ngoài nên Sài Gòn Food cứ bền bỉ làm theo kiểu $\mathrm{DN}$ trong nước: tổ chức các buổi nói chuyện của bác sĩ, giới thiệu đến các trường học, phát sản phẩm cho trường mẫu giáo...

Kinh phí cho nghiên cứu sáng tạo là thách thức đối với nhiều DN. Ông Huỳnh Quang Vinh cho biết, để làm ra những sản phẩm được cho là "đặc sản" miền Tây, Antesco chỉ có 3 nhân sự cho bộ phận R\&D. Trong năm 2015, Công ty chỉ cấp 700 triệu đồng cho công tác nghiên cứu phát triển sản phẩm mới và cũng trong năm qua, nhóm đã nghiên cứu ra 3 sản phâm: trà râu bắp, chả giò chay làm từ đậu nành - bắp non, bắp non tẩm bột chiên.

Bên cạnh những vấn đề trên, nguồn nhân lực cũng là vấn đề đáng lo ngại. Ông Lê Minh Thuận, đại diện Công ty CP Sao Mai, cho rằng, thách thức lớn đối với Sao Mai là nguồn nhân lực chất lượng cao. Sao Mai đã cố gắng hết sức để có chế độ đãi ngộ người lao động nhưng những hạn chế của môi trường kinh tế - xã hội "tỉnh lẻ" khiến công việc tại Sao Mai trở nên thiếu hấp dẫn đối với người tài.

Bà Lê Thị Thanh Lâm cũng đồng tình rằng nguồn nhân lực là một trong những vấn đề quan trọng trong đổi mới sáng tạo: "Nuôi đội ngũ $R \& D$ là vấn đề các $\mathrm{DN}$ cần chú tâm, phải làm sao để họ gắn bó và luôn là người có tâm trong công việc".

Bởi vì, để có được 1 sản phẩm đưa ra thị trường thì đội ngũ nghiên cứu phát triển sản phẩm phải nghiên cứu $5-7$ sản phẩm mới. Vậy nhưng, khi sản phẩm ra thị trường chưa biết có thành công hay không. Nếu những nhân sự làm R\&D không có tâm thì vấn đề bản quyền công nghệ cũng là điều rất đáng lo cho những $\mathrm{DN}$ chịu đầu tư cho công tác đổi mới sáng tạo.

"Bên cạnh đầu tư đổi mới sáng tạo nghiên cứu ra sản phẩm mới, DN cũng cần phải đổi mới quản trị $\mathrm{DN}$. Vì cho dù làm tốt sản phẩm mới nhưng nếu DN không tiếp cận cách quản trị mới thì cũng khó thành công. Hiện Sài Gòn Food đang làm song song 2 việc: bên cạnh đổi mới sáng tạo, nghiên cứu chiến lược sản phẩm, chúng tôi đầu tư xây dựng quản trị thông qua công nghệ ERP", bà Thanh Lâm cho biết. 
